\title{
Analysis of Low-Income Housing Policies and Perfecting Suggestions of Kunming City
}

\author{
Mou Jun \\ Public Administration College \\ Yunnan University of Finance and Economics \\ Kunming, Yunnan, China \\ (moujun77zz@163.com)
}

\author{
Jin Jie \\ Environmental Science and Engineering College \\ Kunming University of Science and Technology \\ Kunming, Yunnan, China, \\ (414980408@qq.com)
}

\begin{abstract}
Housing construction surges in central urban areas of Kunming, and it plays an important role in promoting continuous, healthy and rapid development of national economy. By intensively analyzing low-income housing policies of Kunming City, the thesis tries to provide some suggestions and measures concerning consummating Kunming City's low-income housing planning, construction and administrative policies in respects like capital guarantee, land supply, fiscal taxes and fees, financial support, etc.
\end{abstract}

Keywords-Low-income housing, policy analysis, completion suggestions

\section{INTRODUCTION}

Low-income housing has a not short history in China. However, as for study on low-income housing concepts, some scholars, such as Wen Linfeng1 (2005) and Yang Wei2 (2010), insist on classification according to house types, while some like Hui Bo Zhang Qi (2011)3, and Su Kaicheng4 (2011) recommend classification based on the groups living in lowincome houses. The divergence about the low-income housing concepts in the academia results in diverse study on lowincome housing policies. Some like Song Botong5 (2002) target at low-income housing construction policies, some like Wang Qunhong6 (2010) at housing security system, some like Wang Shuzhen7 (2005) and Wu Di8 (2010) at general issues in

${ }^{1}$ Wen Linfeng, etc., Urban Housing Security, China Development Press, 2007 edition, page 43-47.

${ }^{2}$ Yang Wei, Study on Commercial Bank's Promotion Mechanism on LowIncome Housing Construction-In the Viewpoint of Company Management [D], P 87, master's thesis of Shandong University.

${ }^{3}$ Hui Bo, Zhang Qi, American and Singaporean Low-Income Housing Development Experience and References to our Country "Hainan Finance", $5^{\text {th }}$ issue of 2011 .

${ }^{4}$ Su Kaicheng, Functional Study of County Level Local Government on LowIncome Housing Construction [D], master's thesis of Inner Mongolia University, 2011.

${ }^{5}$ Song Botong, Study on Governmental Housing Construction and Monetary Subsidy Cost Comparison [J], "Journal of Shenzhen University", the $1^{\text {st }}$ issue of 2001 .

${ }^{6}$ Wang Qunhong, Analysis of PEST concerning China Housing Security Systems[J], "Academic Exchange", the $6^{\text {th }}$ issue of 2010

${ }^{7}$ Wang Shuzhen, On Government Failure in Affordable Housing Policy[J], Journal of University of Science and Technology Beijing (Social Sciences Edition), the $4^{\text {th }}$ issue of 2005, page 21-24. housing security implementation at present, some like Jiang Bo9 (2013) and Cao Lijuan10 (2010) propose some measures for completion, and some conclude some proven urban models and analysis models, such as O'Sullivan Arthur11 (1996), Galster,G, (1997). Yue-chin Wong (1998) and Hui Bo (2011). Therefore there are quite many research theories and methods, but there are few discussions on problems of low-income housing policies and consummation suggestions targeting at actual development of urban low-income housing. Some developed countries and areas have amassed abundant and helpful experience in low-income housing construction, and owned mature and complete low-income housing systems and policies, such as the U.S.A., Japan and Singapore121314. As for our country, low-income house appears quite late, so the systems are incomplete, experience is not enough15, etc., but the state has stressed on policies and local governments have made positive exploration during these years, so relatively mature experience and modes 1617 are accumulated. Although domestic and foreign low-income housing systems are different

${ }^{8}$ Wudi, Gao Peng, Dong Jichang, Game Theory Analysis and Governance Study on Illegal Rent of Security Housing [J]. Management Review, 2011,(2).

${ }^{9}$ Jiang Bo, Study on Appropriate Supply of Security Housing, master's thesis of Xi an University of Science and Technology, April 2013.

${ }^{10}$ Cao Lijuan, Thoughts on Completing China Urban Low-Income Housing Policies and Enlightenment about "Chongqing Mode", Theory and Practice, January 2011.

${ }^{11}$ (The U.S.) Arthur O'Sullivan, Urban Economics (the $6^{\text {th }}$ edition), Peking University Press, Beijing, January 2008.

${ }^{12} \mathrm{Wu}$ Guopei, Zheng Hong, Experience in Overseas Low-Income Housing Construction [D], Chinese Finance, Global Outlook, September 26, 2011.

${ }^{13}$ Li Yun, Experience in Overseas Low-Income Housing Construction [D], Social Science Front, the $3^{\text {rd }}$ issue of 2012.

${ }^{14}$ Lu Lei, Overseas Low-Income Housing Legal System and Enlightenment to our Country [D], master's thesis of Tianjin University, June 2011.

${ }^{15}$ He Yuanbin, Reference to Low-Income Housing Policy Experience and Choice of Chinese Development Modes [J], Inquiry int Economic Issues, the $6^{\text {th }}$ issue of 2010 .

${ }^{16}$ Wu Cuiping, Study on Problems of China Urban Housing Security Policies and Countermeasures [D], master's thesis of Xiangtan University, 2010.

${ }^{17} \mathrm{Li}$ Xiao, Research on Urban Medium- and Low-Income Group Housing Security System in China [D], master's thesis of master's thesis of China, 2009 . 
and have strong and weak points, some beneficial experience from low-income security system development and implementation effects of foreign developed countries and several domestic cities of rapid development in this area are of important reference and enlightenment for Kunming to establish and complete the low-income housing security system.

\section{DOMESTIC AND Foreign LOW-INCOME HOUSING DEVELOPMENT EXPERIENCE AND ENLIGHTENMENT}

American low-income housing policies are from permanent federal subsidy system to tackle housing market chaos and housing problems of low-income residents. Rent subsidy was proposed in $1970 \mathrm{~s}$, and private housing has been accelerated through taxation and loan reforms, private housing strategies, "down payment aid plan", etc. In terms of policies, market economy means such as low-interest loans, subsidy, and tax exemption are taken, and furthermore, government allocates funds directly to build the low-income houses, which is called Public Housing Program.

Experience of Japan low-income housing mainly includes: firstly the central government has housing construction department in charge of housing security decision-making, coordination, supervisory administration, etc.; secondly public profit-making housing is provided to "low-income people", which is planned, built and administrated by local governments and the central government offers construction fees, subsidy and rent difference; thirdly a complete indemnificatory legal system is established.

Besides, as for low-income housing of the U.K., firstly the British government intervenes with the housing market directly; secondly the government carries out high welfare policies; lastly private housing is implemented. Germany is mainly focused on market control and social welfare housing. Singapore mainly develops "apartment blocks". That's to say, "private housing" plan and central public fund systems are two major parts for the low-income housing development and development.

Seen from Beijing experience, new low-income apartments may be supplied by new construction, purchasing, long-term rent, etc., of which new construction is the main way and purchasing and lease are the auxiliary way. Wuhan City proposes to resolve housing problems of migrant workers in other ways. Urban village reconstruction should give consideration to residential requirements of migrant workers, and build collective dormitories, etc. to lease to migrant workers under the precondition of meeting urban planning and general land use planning. Chengdu City has published lowincome housing projects under construction and finished ones, targets, apartments to be let out and sold and results, etc. to the public, making sure that low-income apartments are for lowincome groups. Besides, Shanghai, Tianjin, etc. adopt diverse financing ways like real estate investment trust, etc. into lowincome housing construction with urban support, and strive for social security benefit. Chongqing Municipal Government provides apartments for lease to medium and low-income populations, and the government clearly stipulates that the property right of public rental housing is state owned.

Governments of developed countries controlled the lowincome housing construction in infancy, later as housing supply-demand contradiction was gradually alleviated, and the market began to play the key role and government the supporting role. Low-income housing was supported and developed through finance, tax revenue, etc. when the supply and demand was balanced on the housing market, the government began to pay attention to the housing bearing capability of the demand side, for example, formulating corresponding purchasing or rent subsidy policies, i.e. the principle of "market regulation and governmental control". The market did the deployment work. As for governmental control, special institutions were set up, developers got involved in construction, and the actual relation between the government and developer was government dominated partnership, while the relation of the two in ordinary commercial residential building was the administrator and the administrated. When special government sectors built low-income houses instead of developers, complete laws and regulation would restrict and guarantee governmental actions. In the construction mode of low-income housing of countries above, the America government, of which the market economy is the freest, plays the least role, followed by Japan, while low-income housing was the social welfare under the governmental control in Singapore.

\section{ANALySis OF Low-INCOME Housing Construction AND Policies of KunMing}

Kunming, as the capital of Yunnan Province, has the total population about 6.5 million, of which permanent resident population is about 3.6 million, and a considerable part is about 2.9 million without registered Kunming Municipal residence. Quite many people suffer living problems or they are unable to solve the problem independently. Central urban housing construction in Kunming has enjoyed rapid growth since $21 \mathrm{st}$ century, already become the consumption hot spots to expand domestic demands and fast economic growth points, and played a significant role in promoting constant, benign and rapid development of national economy. However, quite severe regional and structural problems are resulted in Kunming real estate market from nationwide skyrocketing real estate prices in recent years, excessive market demands, unreasonable supply structure, etc. The key reason for low-income housing problems in Kunming is because low-income apartments are severely undersupplied and there are no low-rent apartments at all. Low-income housing supply is not implemented because of lack of policies and mechanism for residential apartments of low-income family, and basic living requirements of vulnerable groups are not met. In fact the vulnerable group needs social housing security the most.

Kunming low-income housing construction is developing in a benign circle, and making substantial progress. The housing security system is gradually shaped, but the following major issues exist: 


\section{A. Low-income housing policy system is not coordinated}

Domestic and overseas experience proves that in different housing development stages, the security objects' income levels are changing, so relevant supporting policies should be promulgated. Now the real estate prices in Kunming are pretty high. Middle- and low-income groups are incapable of buying commercial real estate at the current prices and financial conditions. Hence the government is supposed to give play to macro-control, build a great many of low-income apartments, release relevant supporting policy systems based on actual circumstances, expand the scope of people enjoying the lowincome apartments, and make sure that low-income groups in the city realize their goal of "home ownership".

\section{B. Low-income housing is lack of effective management mechanism}

Some problems concerning operation mechanism and actual management of Kunming low-income housing are resulted from many factors, such as diverse residential building functions and complicated security groups. The major reason is the lack of effective management, which leads to huge difference between implementation effects and anticipations of low-income houses, and the fairness is severely impaired. Firstly strict household income survey system is absent, and income is widely used for classification basis due to convenient operation, but it also has obvious defects; secondly at present income transparent in Kunming City is relatively poor, and it is quite difficult and complicated to correctly grasp and measure income, apply for and quit from low-income housing qualification in a timely way.

\section{Land supply for low-income housing is not enough}

Actual construction has already exceeded anticipations due to new development situation requirements of Kunming. The land is increasingly undersupplied, and it is also the case in the main urban area, so it is even more difficult to guarantee the low-income housing land supply.

\section{Funds for low-income housing construction is not available}

Budgetary investment of central finance and provincial level financial aid are allocated according to actual circumstances, but local supporting fund has unstable factors. Firstly net earnings from central urban area land grant in Kunming is quite considerable, and the real estate market there has unstable factors; secondly as the city develops rapidly, public facilities are completed, as-built urban areas are increasingly expanded, and land prices are affected, the city hasn't made correct accounting about net earnings from land grant, so low-rent or low-income housing fund is not available or enough.

\section{E. Low-income housing construction in different areas has disparity}

Central urban area has always been the hot spot in real estate market since it is the economic and political center. However, there is limited land in central urban area, and it is impossible to develop real estate in a great amount, so there are not many development projects, and the project sites are restricted to some extent. Furthermore, development projects are extended to surrounding areas (Chenggong New Area, Airport Economy Area) from main urban areas, and the expanding trend of the urban center is pretty evident.

\section{Suggestions For COMPleting KunMing CITY's LOW-INCOME Housing POLICIES}

In principle non-profit low-income housing projects are encouraged in Kunming, Kunming low-income housing planning, construction and management policies may be completed via fund guarantee, land supply, fiscal taxes and fees, financial aids, etc. To be specific, the following respects are included:

\section{A. Stress on Planning and Reasonable Layout}

According to the principle of coordinated low-income housing construction public policies, construction modes, industrial development and urban construction, and with regard to Kunming urban land resources characteristics and population growth characteristics, the following principles are followed:

1) In terms of space, main urban area and Chenggong New Area should be thought as the key area for new housing construction.

2) In order to solve housing problems of non-permanent populations, focus on building medium- and low-price, medium and small low-income apartments for medium- and low-income people with regard to the construction and layout of industrial parks and logistics parks.

3) Low-income housing (Including public low-rent and low-income housing and shanty area transformation) should choose reasonable construction sites, and focus on areas with relatively convenient transportation and life.

\section{B. Implement Both Low-Rent Housing and Public Rent Housing Construction Mode}

For the convenience of construction and management, Kunming City needs to combine the construction of low-rent housing and public rent housing. Low-income housing indexes and subsidy may be integrated to uniformly plan, select sites and build low-income housing. In principle areas of convenient transportation, complete infrastructures, complete public utilities and convenient employment should be firstly considered for low-income housing. The low-income housing of concentrated construction may be mixed with commercial service facility projects of $15 \%$ total architectural area. Lowincome housing design plans should be optimized to have quality, economical, suitable low-income housing of beautiful environment and complete functions.

\section{The government plays the leading role and takes diverse ways to build low-income housing}

Diverse ways may be adopted to build low-income housing according to actual circumstances of Kunming City. Firstly the government plays the dominating role, and the proportion of low-income housing with the government as the leading role should generally account for over $50 \%$. Secondly 
"government and enterprises build low-income housing" together. The government provides financial aids and preferential policies, enterprises provide land and supporting fund, as-built low-income apartments may be preferentially let out to employees meeting conditions, and the excessive apartments will be let out by the government to the public. Thirdly the government may make overall arrangements about preferential price land and preferential policies, and choose real estate enterprises of strong strengths and good credits to build and operate low-income housing. Fourthly urban shanty area reconstruction continues to be implemented according to local indexes and subsidy policies transmitted by the province to lower levels. Fifthly buy or rent commercial real estate which meet conditions as the source of low-income housing. Lastly focus on peasant households, give consideration to new socialist countryside construction and "expanding cities and reducing villages" pilot work, and promote rural area lowincome housing construction as a whole.

\section{Complete Mechanism and Implement Uniform \\ Management}

Complete low-income house management mechanism, and strengthen supervisory administration over low-income housing admittance exam \& check, allocation, use, etc. Firstly credit reference system is recommended. Gradually establish housing security administration information system, complete low-income housing files, and reinforce dynamic monitoring over security object family apartments, economic conditions and changes. Secondly regulate the admittance review. Further complete low-income housing application, exam \& check, publicity, waiting, rent and after-rent management system, complete exam \& check mechanism, strengthen operating supervision, and make sure openness, transparency, fairness and justice. Improve the allocation efficiency. If the lowincome housing and auxiliary facilities are completed and available for living, arrange security objects to live in within one month, so as to avoid unused state-owned assets. Thirdly implement fixed rent of different levels. Implement uniform management over public lease housing operation, classify them and fix the rent, and reasonably decide the rent levels.

\section{E. Complete Low-Income Housing Exit Mechanism}

When the security object' $\mathrm{s}$ family income and housing conditions change and don' t meet conditions to live in lowincome housing, carry out dynamic management. Firstly implement "sale after rent" to purchase the original public rent housing, and the purchased public rent housing is under management of economically affordable housing. In principle, the purchased public rent housing cannot be transferred or sold on market, but it may be inherited by direct relatives. If the transfer is necessary, the government enjoys the priority to buy it back. Secondly if the low-rent house residents have income beyond the scope of public rent housing security, the residents return the public rent apartments or pay the rent according to market standards. Anyone providing false data to purchase and rent low-income housing will be ordered to exit once all circumstances are proved true.

\section{F. Promote Low-Income Housing System Building Comprehensively in Kunming}

Comprehensively promote public services and auxiliary facilities construction around low-income housing, and gradually shape relatively complete the governmental housing security system. Provide "all necessary security" to households receiving subsistence allowances and households with living difficulty, speed up to resolve living problems of urban medium- and low-income households, fresh employees, migrant workers, etc., build more low-income housing and commercial apartments of restrictive prices, and have diversified low-income housing and commercial apartments of restrictive prices. The goal is to improve living conditions of most low-income households and part medium- and lowincome households, and provide shelters for all people. Consecutively establish and complete low-income housing policies, and housing technical support systems, constantly accelerate low-income housing legislation, legally strengthen housing security responsibilities of governments of all levels, establish and complete housing security organizations, and accelerate Kunming "five-in-one" low-income housing information management platform involving residential apartments, prices, individuals, incomes and credit information.

\section{ACKNOWLEDGMENT}

Thanks go to units, such as Yunnan Province Housing and Rural-Urban Construction Department, Kunming Municipal Housing and Rural-Urban Construction Bureau, Kunming Municipal Housing Security Bureau, Kunming City Public Rent Housing Development \& Construction Management Co., Ltd., Kunming Municipal Statistical Bureau, Bank of China, Yunnan Branch, and relevant people for the support and help.

\section{REFERENCES}

[1] Wen Linfeng, etc., Urban Housing Security, China Development Press, 2007 edition, page 43-47.

[2] Yang Wei, Study on Commercial Bank' s Promotion Mechanism on Low-Income Housing Construction-In the Viewpoint of Company Management [D], P 87, master's thesis of Shandong University.

[3] Hui Bo, Zhang Qi, American and Singaporean Low-Income Housing Development Experience and References to our Country "Hainan Finance", 5th issue of 2011.

[4] Su Kaicheng, Functional Study of County Level Local Government on Low-Income Housing Construction [D], master's thesis of Inner Mongolia University, 2011.

[5] Song Botong, Study on Governmental Housing Construction and Monetary Subsidy Cost Comparison [J], "Journal of Shenzhen University”, the 1st issue of 2001.

[6] Wang Qunhong, Analysis of PEST concerning China Housing Security Systems[J], “Academic Exchange", the 6th issue of 2010

[7] Wang Shuzhen, On Government Failure in Affordable Housing Policy[J], Journal of University of Science and Technology Beijing (Social Sciences Edition), the 4th issue of 2005, page 21-24.

[8] Wudi, Gao Peng, Dong Jichang, Game Theory Analysis and Governance Study on Illegal Rent of Security Housing [J]. Management Review, 2011,(2). 
[9] Jiang Bo, Study on Appropriate Supply of Security Housing, master' s thesis of Xi'an University of Science and Technology, April 2013.

[10] Cao Lijuan, Thoughts on Completing China Urban Low-Income Housing Policies and Enlightenment about "Chongqing Mode", Theory and Practice, January 2011.

[11] (The U.S.) Arthur O'Sullivan, Urban Economics (the 6th edition), Peking University Press, Beijing, January 2008.

[12] Wu Guopei, Zheng Hong, Experience in Overseas Low-Income Housing Construction [D], Chinese Finance, Global Outlook, September 26, 2011.

[13] Li Yun, Experience in Overseas Low-Income Housing Construction [D], Social Science Front, the 3rd issue of 2012.

[14] Lu Lei, Overseas Low-Income Housing Legal System and Enlightenment to our Country [D], master' $\mathrm{s}$ thesis of Tianjin University, June 2011.

[15] He Yuanbin, Reference to Low-Income Housing Policy Experience and Choice of Chinese Development Modes [J], Inquiry int Economic Issues, the 6th issue of 2010 .

[16] Wu Cuiping, Study on Problems of China Urban Housing Security Policies and Countermeasures [D], master' $\mathrm{s}$ thesis of Xiangtan University, 2010.

[17] Li Xiao, Research on Urban Medium- and Low-Income Group Housing Security System in China [D], master' $s$ thesis of master' $s$ thesis of China, 2009. 